\title{
Vidas tomando corpo
}

\author{
Lives taking body
}

Janyne Sattler'

\begin{abstract}
Resumo: Este ensaio discorre sobre os conceitos de 'corpo' ou 'corporeidade' e 'criaturidade', inspirados na abordagem conceitual e metodologicamente wittgensteiniana do filósofo australiano Raimond Gaita e suas aproximações com a literatura de J.M. Coetzee, para pensar em uma proposta que se quer como metaética, almejando, no entanto, uma alternativa às "éticas animais" hodiernas ao estabelecer como condição básica para a moralidade - estruturada sobre o campo do significado - do corpo vivo. Trata-se de salientar o viés político do corpo e da linguagem, ao perscrutar os significados de nossas relações com a criaturidade humana e não humana em vista de um mundo mais vivível para nós e para eles.
\end{abstract}

Palavras-chave: Corpo; Criaturidade; Animalidade; Gaita; Coetzee

\begin{abstract}
This is an essay concerning the concepts of 'body' or 'embodiment' and 'creatureliness', inspired by the conceptual and methodological Wittgensteinian approach of the Australian philosopher Raimond Gaita and his reflections about J.M. Coetzee's literature. My main aim is here to think about an alternative to the so called "animal ethics" from a metaethical perspective by establishing as a basic condition to morality - as structured on the realm of meaning - the concept of the 'living body'. It is a matter of emphasizing the political bias of the body and of language, by examining the meanings of our relations to human and non-human creatureliness in view of a more livable world for us and for them
\end{abstract}

Keywords: Body; Creatureliness; Animality; Gaita; Coetzee

A única vida que existe é esta aqui. Que a gente reparte com os animais.

Coetzee

O contexto da afirmação de Lucy Lurie em Desonra é o contexto de um diálogo a respeito de sua escolha pela vida do campo e pela vida de dedicação aos animais não humanos, contra alguma ideia qualquer de superioridade a partir da perspectiva intelectualizada, e talvez até mesmo instrumentalizada, de David Lurie sobre o "pessoal do bem-estar animal" e o seu "cristianismo" de um certo tipo. Lucy afirma que tenta seguir o exemplo dado por Bev Shaw, que mantém uma clínica para tratamento e, muito mais frequentemente do que se poderia desejar, para eutanásia de animais em seu último recurso de dignidade: "Repartir alguns dos nossos privilégios humanos com os bichos. 
Não quero voltar numa outra vida como cachorro ou como porco para viver como os cachorros e porcos vivem com a gente agora"1.

Esta é a única vida que há, uma vida compartilhada com os animais não humanos. Mesmo assim, parecemos ser incapazes de vidas mais vivíveis. Para nós e para eles. Tornamos quase impossível o desfrute da singularidade do presente com o nosso amplo espectro de crueldades e indiferenças, apesar, aliás, dos avanços em alguma medida significativos das teorias éticas devotadas a pensar os nossos deveres e os direitos para os humanos e para os não humanos.

Talvez, e essa será minha sugestão ao longo do que se segue, essa nossa inaptidão para um mundo mais vivível - expressão utópica que adapto e tomo de empréstimo de "um modo de viver bem no mundo" de Donna Haraway ${ }^{2}$ - advenha de um certo tipo de inaptidão conceitual; não única e unilateralmente, é claro, mas de modo muito marcado por nossa perspectiva filosófica antropocêntrica, androcêntrica e moral e politicamente desengajada do mundo, da vida e da realidade a um palmo do nosso nariz. Uma inaptidão oriunda do privilégio de alguns conceitos sobre outros e da saliência de uma normatização supostamente neutra, imparcial e pretensamente universal, em detrimento das vidas de fato aqui vividas. Em detrimento, portanto, de vidas vividas em seus corpos.

Minha asserção aqui é a da necessidade de uma reflexão sobre a 'vida' que leve a sério a inescapável corporeidade de nossa posição no mundo como o fundamento incondicional para qualquer proposta ética e política que se enseje desenvolver em direção a um horizonte no qual "viver como um cachorro" já não signifique humilhação e indignidade.

Uma filosofia corporificada não é coisa que se vê canonicamente, sendo um determinado tipo de razão desencarnada o ideal e o critério de uma reflexão tomada como séria, objetiva e desinteressada. Tenho consciência de que esta é uma afirmação bastante genérica a respeito da tradição filosófica, mas o pano de fundo aqui, para fazer um recorte inacabado, é indubitavelmente aquele da Modernidade, de uma construção que se nomeia como racionalista e iluminista para uma ampla gama de filósofos - homens, brancos, europeus - e sobre a qual está assentada ainda contemporaneamente a nossa concepção de "prática" filosófica.

Há desvios do cânone, no entanto - ou daquilo que nós hoje tomamos como cânone. Se podemos localizá-los em pontos diversos de divergência ao longo da história da filosofia, alguns destes desvios são eminentemente recentes e se inscrevem também contra a vigência de um academicismo despersonalizado e contra a pretensa imparcialidade da reprodução meramente exegética do discurso filosófico. Para algumas destas posturas, importa pensar que nossas ideias tomam corpo, - literalmente - ou que os marcam indelevelmente ao tornálos, quando vem bem a calhar, corpos "desviantes". Com o que, são estes últimos os corpos que passam a ser excluídos, inconsiderados, oprimidos, invisibilizados.

As ideias que tomam corpo e se materializam no mundo são hegemonicamente aquelas da branquitude masculina, cuja legitimidade corpórea assume um caráter universalizante enquanto aparece, obviamente, como o único corpo inquestionado; e é por isso, é claro, que sua abstração subjacente não lhe coloca problemas.

Esse é o teor da denúncia de algumas das reflexões divergentes que eu gostaria de trazer à foro para compor um quadro discursivo evidentemente ancorado no mundo e na vida e, por isso, moral e politicamente implicado em suas reverberações. É também por estar assim fundeado que este discurso é ele mesmo atravessado pela interseccionalidade, tanto dos corpos concretos assim situados na realidade, quanto também metodológica e epistemologicamente. Não é arbitrário, portanto, o entrecruzamento aqui proposto de questões que são concomitantemente morais, políticas, epistemológicas e literárias, para

${ }^{1}$ COETZEE, Desonra, p.58.

${ }^{2}$ HARAWAY, Saberes localizados: a questão da ciência para o feminismo e o privilégio da perspectiva parcial, p.15. 
se pensar em rede ou em teia - de modo interseccional, por conseguinte - em perspectivas animalistas, feministas e, possivelmente também, ecofeministas.

Para cada um destes pontos de intersecção, é do viés político do 'corpo' - e depois do 'corpo vivo' - que se trata. No que segue, minhas reflexões estarão centradas sobre o modo como o filósofo australiano Raimond Gaita - desde uma abordagem informada por lições metodológicas e conceituais wittgensteinianas - concebe a própria linguagem como estando estruturada sobre o significado do 'corpo' em O cão do filósofo, com algumas inflexões aí compartilhadas pela personagem Elisabeth Costello de $A$ vida dos animais de J.M. Coetzee, e alguns aportes subsidiários oriundos da epistemologia feminista.

Eu gostaria de sugerir que Raimond Gaita é um filósofo da 'corporeidade'. Ele talvez preferisse o termo 'criaturidade' em seu lugar, mas creio que em vários momentos estes conceitos possam funcionar de modo intercambiável. A 'criaturidade' talvez seja estruturalmente anterior ao conceito de 'corpo', já que é sobre a criaturidade compartilhada entre animais humanos e não humanos que se estabelece aquilo que Gaita chama de "campo do significado", este espaço ou território conceitual sobre o qual se constrói a moralidade, esta não tendo, por isso, em qualquer sentido que seja, um caráter a priori ou um caráter externo às nossas maneiras de falar e de reagir à superfície dos corpos - ao modo como vemos o outro, animal ou humano, como um corpo.

A linguagem é aqui, obviamente, concebida como uma construção humana, um dado da cultura, e está sempre alicerçada sobre contextos e práticas conversacionais relativamente aos quais faz sentido a pergunta pelo significado - das nossas ações, respostas, expressões e conceitos comuns - e que nos permitem, antes de mais nada, o empreendimento mesmo da reflexão moral e política. É desde aí que Gaita concebe o que está fazendo como sendo uma investigação metaética. Para ele, refletir sobre a moralidade é refletir sobre o campo do significado cujos conceitos críticos fundacionais e estruturais (ou, alternativamente, cujos valores absolutos) nos possibilitam "ver as coisas como elas são”. Que possamos ver as coisas como elas são é, aliás, talvez, o principal motivo de qualquer incursão de nossa parte ao campo do significado. Gaita fala aqui de nossa profunda necessidade de lucidez e de sobriedade quando se trata do entendimento dos fatos da condição humana - e animal, - quando não nos deixamos auto-enganar pela vaidade ou por nosso recorrente "ego obeso"; lucidez, sobriedade e profundidade constituindo-se como critérios para o tipo de reflexão moral vislumbrada contra o que ele chama de "cegueira semântica" - e que pode ser a cegueira de qualquer pessoa incapaz de ultrapassar a estreiteza dos seus preconceitos ao conceber os "outros" como apenas parcialmente humanos à altura de sua própria humanidade, ou a cegueira de algumas reflexões reducionistas típicas da filosofia moral em sua ânsia transcultural e universalista.

A ideia de que muitas teorias éticas - e também aquelas que poderíamos chamar de "éticas animais" - participam dessa cegueira semântica se deve às concepções subjacentes às suas pretensões normativas e que têm a ver, por um lado, com as noções de 'agência moral' e 'racional', de 'sujeito', de 'pessoa', etc., cujos recursos conceituais se esgotam tão logo surja a necessidade de contextualização e individualização na aplicação (ou até mesmo na descrição) de suas normas, princípios ou lei morais e, por outro lado, embora não de modo desvinculado, com a pretensão desencarnada da agência moral imparcial, cujo olhar pareceria ser aquele do "ponto de vista do universo", mas que pode fazer as vezes de ponto de vista de Deus ou "do lugar algum” que deseja ser, no fundo, o "lugar do todo". 
Para se ver as coisas como elas são é preciso estar "no meio das coisas", no mundo, e não fora dele. Na verdade, é isso o que significa, justamente, habitar um mundo, e nós o fazemos como o fazem as demais criaturas: de modo corporificado. Os conceitos fundacionais e estruturantes do campo do significado no qual se encontra a moralidade estão todos ancorados sobre o 'corpo' como suporte dos fatos daquilo que chamamos de condição humana, muitos dos quais são compartilhados com os animais não humanos não de modo meramente a eles extensivo, diz Gaita, mas de modo igualmente fundacional e estruturante: vulnerabilidade, velhice, afetividade, sexualidade, individualidade. O comentário sobre estes conceitos a seguir é breve, mas já indicativo do tipo de demanda imposto por nossos modos de percepção da alteridade.

A criaturidade supõe uma vulnerabilidade intrínseca "ao azar", que pode assumir aspectos mais ou menos violentos e letais, mas que tem a ver igualmente com a degradação corpórea do envelhecimento. Habitamos um mundo conjunto no qual estamos expostos fisicamente e psicologicamente aos abusos e às opressões, mas também ao desprezo, à solidão e ao medo. No entanto, esta vulnerabilidade é também determinada por nossos vínculos, nossos laços e afetos, cujo “azar” aqui é de outra ordem, mas que incide diretamente no significado de algumas de nossas ações e respostas, e maneiras de falar sobre as coisas - no modo como respondemos à perda daqueles que amamos, por exemplo, ou no modo como construímos nossa identidade. A sexualidade é, neste sentido, igualmente determinante para o modo como respondemos aos outros, sobretudo porque ela exige o reconhecimento de uma individualidade de caráter precioso e insubstituível - a concepção dos seres humanos como únicos e insubstituíveis - e nem mesmo o sexo casual, segundo Gaita, admite o tipo de distanciamento às vezes imaginado como possível, como desresponsabilização - ou, dito de outro modo, como ausência de responsividade. Sem falsos moralismos, a ideia aqui é a de que a individualidade é indelevelmente baseada e marcada por afetos, e a vivência da sexualidade é, por isso, igualmente dependente do reconhecimento do sexo como resposta ao outro - como resposta, aliás, a um outro corpo singularmente vivo. Daí, justamente, o horror particular e incomparável do estupro em sua violação a um ser sexual individualizado, cuja preciosidade é sempre tangenciada pela vulnerabilidade de uma condição corpórea ao mesmo tempo aberta e responsiva.

É portanto sobre o corpo que se fundamentam os conceitos da nossa criaturidade compartilhada: um corpo vulnerável, um corpo que envelhece, um corpo que possui laços e afetos, desde a maternidade e a paternidade ou a ausência delas até o sexo, um corpo que é único e insubstituível. Desde aí o significado de algumas de nossas práticas e maneiras de ver e de falar sobre os outros: o fato de darmos nomes às pessoas ao invés de etiquetas numeradas, o fato de celebrarmos nascimentos, aniversários, e mortes, o fato de providenciarmos aos corpos mortos um fim adequado e de pensarmos os corpos vivos como portadores de 'humanidade'; desde aí o significado de horror absoluto quando tais fatos são desrespeitados. É isto um homem? nos dá aqui o exemplo por excelência.

Para Gaita, é o entendimento dos significados que nos permite ver as coisas como elas são; ou melhor, é a pergunta pelo significado que orienta a nossa reflexão moral e a natureza conversacional e interrelacional dos nossos julgamentos e das nossas respostas morais. O que, por exemplo, significa "errar com alguém”? O que significa "cair em desgraça”? O que significa perder alguém, ou rememorar com ritos uma vida que não existe mais? Qual é o significado de nossas cerimônias fúnebres? Mas qual é o significado, por outro lado, do abandono dos velhos, dos “indigentes”, dos marginais? O que significa a demanda por dignidade? O que significa "cuidar" de alguém?

É neste sentido que a pergunta pelo significado é ela mesma moralmente reflexiva - já que interroga, via necessidade de lucidez e de sobriedade, os valores absolutos que iluminam os fatos da condição humana e a imposição, em termos quase socráticos, de uma "vida 
examinada”. Estes valores absolutos não devem, porém, ser compreendidos como "universais”, já que não pretendem normatizar universal e imparcialmente o nosso modo de compreensão ou a nossa atitude para com o mundo e para com a vida. Eis porque são também moldados por conceitos críticos, contextualizados e circunstanciados. Eis porque, além disso, constituem a amplidão do território conceitual cujo espírito é a superação daquela "cegueira semântica" presente no ponto de vista parcial e preconceituoso - teórico, inclusive.

A perspectiva de Gaita preconiza, assim, uma linguagem - que sou eu que nomeio abaixo como uma linguagem responsiva - substituta àquela da estreiteza normativa e que vem sobretudo tornar visível o outro em sua realidade singular, única e insubstituível, cuja corporeidade, no entanto, é o fato indelével a partir do qual se dá sua comunidade de criatura com todos os outros viventes. $\mathrm{Na}$ delicada teia de significados da moralidade, trata-se de uma linguagem do amor, da justiça, da piedade e da compaixão, da dignidade, da generosidade e da beleza. E se estes são valores absolutos no sentido de não serem passíveis de barganha no campo do significado (se o amor se dá sob múltiplos matizes, ele jamais significa outra coisa, contudo, senão aquilo que cai sob sua conceituação) estes são valores necessariamente abertos a reações e respostas localizadas e particulares, cuja caracterização local e particular é precisamente o que ajuíza a nossa linguagem quando falamos sobre o que significa viver uma vida. Assim, se não há aí qualquer pretensão de normatividade, esta linguagem não é, contudo, arbitrária, mas está justamente fundada sobre nossa forma de vida humana.

A premissa para a compreensão do campo do significado como fundacional para a moralidade é a de que o 'corpo' incide diretamente na constituição dos nossos conceitos. Ele é o conceito subjacente a toda e qualquer conversa sobre sofrimento e prazer, sobre juventude e envelhecimento, sobre sexualidade e violência sexual, sobre maternidade e paternidade, sobre abandono e afetividade, sobre liberdade e encarceramento, sobre preconceitos e visões distorcidas da alteridade, sobre humanidade e animalidade. 'Corpo' é o conceito constitutivo básico da nossa linguagem, mesmo quando nossa linguagem nos leva aos domínios de uma reflexão filosófica pretensamente desencarnada e cética - cuja suposição compartilhada é o que faz cético e não cético reagirem do mesmo modo ao 'corpo vivo'. 'Corpo' é o conceito constitutivo básico da nossa linguagem e que estrutura assim o todo de nossas respostas ao mundo, com o que ela é, por isso, necessariamente, uma linguagem corporificada. Nossas respostas ao mundo se dão, portanto, como respostas à sua superfície, e era isso o que Wittgenstein queria dizer - solapando o discurso cético - ao chamar nossas atitudes para com os seres humanos de "atitudes para com uma alma”. É exatamente também o modo como respondemos aos animais não humanos. Não respondemos a eles como respondemos a pedras, artefatos, e mesmo a plantas, mas o fazemos como "para com uma alma". Neste sentido, também o 'corpo' do animal não humano é estruturante relativamente a nossa linguagem. Não se trata, insiste Gaita, de imaginar que a compreensão da nossa corporeidade e do seu aspecto determinante para os nossos modos de falar sobre a vida se tenha desenvolvido restritivamente a nosso respeito para uma ulterior extensão dos seus conceitos aos animais não humanos, mas de perceber que a compreensão da nossa corporeidade e de nossas respostas para com o mundo é fundada também por nossa criaturidade compartilhada, por nossas relações para com os animais, e por nossa co-habitação mundana. Que os animais não humanos são sencientes não é a conclusão de um processo reflexivo ou filosófico qualquer desde a nossa própria capacidade sensível a eles aplicada, mas uma suposição inquestionada e inquestionável estruturada por nossas reações e respostas de superfície, por nossa linguagem corporificada, por nossas atitudes para com os corpos vivos como corpos vivos.

É ao corpo vivo que reagimos como "para com uma alma”. Nada em nossos modos de falar e responder aos animais não humanos nos capacita a percebê-los como objetos 
ou como autômatos ou como pedras silenciosas - nem mesmo, aliás, nossa crueldade ou nosso comportamento mais ou menos esquizofrênico ou hipócrita, quando adoramos uns e comemos outros, ou quando os condenamos aos laboratórios e mesas de pesquisa apenas para voltarmos aos nossos "bichos de estimação" em casa. Nada nesses comportamentos e atitudes cotidianas, remontando à longa história de convivência, nos capacita a perceber os animais não humanos como in-corpóreos, não-corpóreos ou desen-carnados. É sobre o corpo vivo que reside o significado das nossas atitudes e respostas para com a animalidade, bem como o significado do tratamento que a ela outorgamos, seja ele a deferência, a compaixão ou a crueldade.

Creio que Gaita compartilhe com Elisabeth Costello - a romancista palestrante da reflexão meta-ficcional e meta-filosófica de Coetzee em $A$ vida dos animais - o seu desprezo para com os modos insistentes pelos quais a filosofia moral, com o suporte de um determinado tipo reducionista de teoria socioevolucionária e/ou bio-neuropsicológica e behaviorista, tem tentado justificar - senão mesmo legitimar - e legislar o nosso entendimento sobre a animalidade bem como o seu consequente agenciamento moral e político (e jurídico, também, muitas vezes). No pacote teórico rechaçado não estão apenas um resiliente mas envelhecido cartesianismo ou um ceticismo irresoluto conjugado com algum argumento de ordem religiosa e ordenamento hierárquico dos céus aos infernos passando pela prerrogativa humanista, mas acabam entrando também aquelas teorias cuja centralidade é uma defesa animal. Não é à toa que Coetzee esteja dialogando com Peter Singer mas tangencialmente também com Tom Reagan, e que Gaita seja crítico da centralidade do juízo especista sobre as nossas ações e relações para com os animais não humanos. O que todas estas posturas esquecem ou ignoram é o pressuposto conceitual básico sobre o qual repousam todas as nossas atitudes - morais, imorais e políticas que é aquele do 'corpo vivo'. Costello fala eloquentemente dos animais como 'cheios de ser', full of being. Contra uma dimensão intelectual ou imaginativa de sua vivência, tratase de enxergá-los a partir de um conceito pervasivo de 'vida', que despreza e rejeita a parcialidade antropocêntrica dos critérios de entendimento e de consideração da animalidade - tais como muitos daqueles advindos da "filosofia moral" em sua maior ou menor aproximação com a vivência, os interesses, as capacidades e potencialidades humanas. Bastaria, desde o ponto de vista da moralidade, estar 'cheio de ser' - algo que para o próprio Singer parece soar como um igualitarismo demasiado radical, conforme sua interlocução com Coetzee no livro citado. Mas é claro que isso também significa que se trata de um conceito corporificado, encarnado, de 'vida'. "Todo seu ser está na carne viva”, diz Costello. Ela está respondendo àquela reiterada ideia de que os animais não humanos são incapazes de temer a morte porque dela não têm consciência ou previsibilidade, com o consequente corolário de que sua vida lhes é menos valiosa - e a supostamente decorrente permissibilidade de nossas ações para com eles. Mas a vivência na 'carne viva' não caracteriza apenas a sua condição de mortalidade na iminência da violência, do sofrimento ou da morte, mas toda a sua condição de criaturidade. Está na carne viva a sua fome, a sua alegria, o seu movimento, o seu afeto, a sua liberdade, o seu confinamento, o seu medo, a sua perda. A sua vida é o seu corpo e é o seu corpo que é cheio de ser, assim como o nosso - assim como a nossa igual condição de criaturas corporificadas. A 'vida' aqui é inescapável e necessariamente encarnada, e nada neste conceito nos permite qualquer distinção hierárquica entre "nós” e “eles”. Para Costello, assim como para Gaita, ainda que sejamos criaturas de imaginação e de reflexão, é no entanto o corpo vivo, o corpo cheio de ser, o ponto fulcral sobre o qual se ancoram nossas vivências no mundo e nossas respostas aos animais humanos e não humanos com os quais o habitamos. Costello sugere que se "caminhe lado a lado - com os flancos emparelhados - de um animal tangido 
ao encontro de seu executor" ${ }^{3}$ se suas considerações filosófico-poéticas soarem ainda insuficientes aos ouvidos antipáticos do empedernido filósofo cético - ou humanista, ou utilitarista, ou normativista, ou universalista, etc. Talvez apenas no flanquear dos corpos vivos sejamos capazes de perceber o significado da dignidade como valor absoluto aplicado à vulnerável corporeidade que compartilhamos com os animais, mas também com todos aqueles seres humanos tornados invisíveis pela hostilidade de nossas construções linguísticas desdobradas em "éticas” e "políticas” excludentes: dignidade e honra dos corpos vivos vividos em sua plenitude de ser cujo reflexo me parece permitir também pensar no modo como são tratados estes corpos quando já desprovidos de vida, e no profundo desrespeito, portanto, de nossa cultura carnivorista - que reverbera outros "ismos" de exclusão mutuamente implicados. Se a muitos corpos vivos não se outorga a dignidade de sua própria preciosidade - a preciosidade que cada ser sentiria, segundo Costello, na carne viva - a muitos outros tampouco se permite a integridade do corpo morto. Evidentemente, nós devemos aqui pensar não apenas nos animais não humanos, já que a muitos corpos negros, a muitos corpos indigentes, a muitos corpos imigrantes, se atribui também uma animalidade permissiva de seu abandono - já em vida, muitas vezes.

A 'honra dos corpos' está implícita em todas as falas de Elisabeth Costello, já que a ideia dos corpos vivos, cheios de ser, é atravessada pelo cotidiano dos abatedouros e pela incômoda metáfora do "holocausto animal". Mas Coetzee é muito mais transparente a este respeito nas passagens de Desonra que se referem a animais mortos - os cães eutanasiados por Bev Shaw, que são levados da clínica ao incinerador de um hospital por David Lurie, já em sua derradeira etapa de desgraça. Toda a questão neste ponto gira em torno do tratamento dado aos corpos dos cães em seu invólucro plástico, sendo impossível para Lurie permitir que sejam batidos e quebrados, estando ele agora "a serviço de cães mortos". Mas Lurie não parece de fato disposto a levar a cabo sua visão de mundo, "um mundo em que homens não usam pás para reduzir corpos a uma forma mais conveniente de se eliminar", já que ele está salvando "a honra dos corpos porque nenhum outro idiota se dispõe a fazer isso". E isso não responde de fato a sua pergunta: "e o que sabem os cachorros acerca de honra e desonra?"4.

Gaita não consideraria isso uma questão de idiotice, e tomaria a pergunta de Lurie como uma pergunta pelo significado de 'honra' e 'desonra', pelo significado da honra e da desonra dos corpos vivos e dos corpos mortos, e como uma pergunta sobre o significado de nossos atos como sendo distintos relativamente a animais humanos e não humanos: "A questão que importa agora não é como se deve tratar os cães ou se devemos evitar-lhes a desonra, mas o que pode significar desonrá-los, especialmente quando já estão mortos"5. A questão não é, portanto, o tipo de normas que podemos construir a este respeito - a legislação moral de nossos atos - porque não parecemos sequer ainda saber o que significa para nós e para os animais não humanos salvaguardar a corporeidade de ser molestada, insultada e desonrada em sua condição de vulnerabilidade e de individualidade, em sua condição de vivência na carne viva e em sua condição de corpo outrora habitado "por uma alma" - condição que rege nossas atitudes e nossas respostas diferenciadas à criaturidade. Trata-se, assim, de uma questão colocada naquele espaço ou território conceitual estruturante e fundacional da moralidade cujos valores e conceitos críticos informam e ajuízam a nossa compreensão em relação à visão das coisas como elas são, "uma reflexão sobre como vivemos nossa vida com essa parte da linguagem (...)”6.

\footnotetext{
COETZEE, A vida dos animais, p.78; tradução modificada.

4 COETZEE, Desonra, p.112; tradução modificada.

5 GAITA, O cão do filósofo, p.112; grifo meu.

${ }^{6}$ GAITA, O cão do filósofo, p.113.
} 
Se nossa inaptidão para um mundo mais vivível advém também daquilo que chamei de um tipo de inaptidão conceitual, talvez pudéssemos repensar os nossos critérios de entendimento a respeito de como as coisas se passam em nossas relações para com a alteridade, humana e não humana, e os nossos critérios para uma responsividade responsável e engajada no mundo ao tomar como o ponto fundacional e medular de nossa complexa e delicada teia conceitual o significado aqui engendrado pelo conceito de 'corpo vivo'. Mas isto requer que o empreendimento de qualquer projeto ético e político que se queira em algum sentido interseccional e animalista - e em algum sentido também ecofeminista - esteja aberto às necessidades de uma profunda reforma do nosso território filosófico-gramatical e conceitual. Porque a interseccionalidade e a complexidade de nossa vida moral exige sobrepujar as pretensões homogeneizantes de nosso arrogante antropocentrismo. E isso implica muito mais do que tem estado em jogo nas "éticas animais" e nas "filosofias morais" herdeiras da Modernidade, porque envolve uma reavaliação crítica dos usos de nossa linguagem - segundo um critério freiriano, por exemplo, de saber se ela é inclusiva ou excludente. É neste sentido que o presente ensaio ecoa as pretensões metaéticas de Raimond Gaita também na senda já palmilhada anteriormente pela postura wittgensteiniana de outros de meus trabalhos.

Contra o privilégio de uma conceituação instrumentalizada e hierarquizada de uma senciência que se legitima tanto mais quanto mais se aproxima da consciência reflexiva humana, trata-se, de alguma forma, de horizontalizar nossas reflexões morais a partir de nossa corporeidade e criaturidade compartilhada - de tal modo que não se possa mais falar da "ampliação da comunidade moral" desde o ponto de vista concêntrico que é regulamentado por questões de agência moral, o que já parece pressupor condescendência de nossa parte e uma espécie de arrogante caridade. Alternativamente, é sobre o conceito de 'corpo vivo' que se pretende aqui estruturar toda a reflexão sobre a moralidade, um conceito que é portanto gramaticalmente, e segundo o proponho aqui, metodologicamente também, anterior a qualquer ajuizamento sobre as finalidades da moralidade. Ou seja, 'corpo' - mas se preferirmos também 'corporeidade' e 'criaturidade' - é o conceito subjacente à construção ancorada na linguagem e no mundo de nosso entendimento sobre o significado da vida, humana e não humana. Ou ainda, o conceito subjacente à pergunta sobre o que significa viver em um corpo intrinsecamente vulnerável e $o$ que significa responder a outros tantos corpos igualmente vulneráveis. O que significa tornálos visíveis em sua condição de criaturas. E é o compartilhamento desta condição em um mundo dado a todas as criaturas sem exceção, cujo azar é conjuntamente aquinhoado, o que nos permite vislumbrar um projeto ético e político de fato interseccional e animalista. Porque basta, para nossas considerações desde o ponto de vista da moralidade, estar 'cheio de ser'.

Note-se que aqui qualquer angústia acerca das supostas lacunas normativas de uma investigação como esta é sintomática de um determinado tipo de conceituação e de linguagem que se vê ainda cativa da esperança de uma ordenação idealmente universal, que venha a resolver todos os nossos problemas e não faça caso das minúcias da complexidade. Também a pergunta pelos limites de consideração da 'vida' é uma pergunta simplificadora de nossas reflexões - e ações consequentemente. 'Estar cheio de ser' é uma expressão manifestamente vaga, e algumas objeções neste sentido poderiam facilmente nos levar à consideração não apenas dos animais não humanos, mas de aranhas, borboletas, moscas, abelhas. No entanto, por que não? Sem cair em qualquer tipo de panteísmo ou de ecologismo, é o que Gaita está fazendo. Não no sentido normativo de condenar moralmente a todos nós que matamos aranhas ou moscas ou baratas e outros 
insetos, mas no sentido da pergunta pelo significado de nossos atos, no sentido de nos dispormos a considerar o que significa arrancar as asas de uma mosca, pisotear com prazer um formigueiro, ou esmagar um besouro com uma vareta. São considerações complexas que não podem ser de antemão simplesmente respondidas e decididas unilateralmente. Mas isto só constitui um problema para o tipo de inaptidão conceitual aqui denunciado. Afinal, como afirma Gaita, "a sutileza da teia irrita algumas pessoas. Sua fragilidade lhes faz perder a coragem"7.

Uma das primeiras assunções a ser reconhecida, neste sentido, é aquela de que nossa linguagem é, inescapavelmente, corporificada. Sendo um dado e uma construção cultural humana, ela não existe como idealidade abstrata e posteriormente apreensível a partir dos emaranhados inabitados do universo. Ela não é neutra em nenhuma de suas instâncias. E para isso nós não precisaríamos sequer ir tão longe quanto todas as denúncias das leituras feministas da epistemologia e da filosofia da ciência - muito embora isso seja infelizmente ainda absolutamente imprescindível. Bastaria perceber que ela não pode, em qualquer sentido que seja, prescindir de um corpo. Antes de mais nada, de um corpo que é a estrutura fundacional para todos os conceitos que nos permitem ver as coisas como elas são, a partir de sua natureza interrelacional - os conceitos ligados à nossa criaturidade - e, por isso mesmo, em seguida, de um corpo que é superfície para reações e respostas “a uma alma” e, portanto, superfície para nossa linguagem, para nossos modos de falar sobre as coisas, para a compreensão do campo do significado e, desde aí, para a compreensão do significado da moralidade. Bastaria perceber, então, que nossas atitudes para com a alteridade, atitudes que caracterizamos como compassivas, generosas, piedosas, amorosas ou, ao contrário, como cruéis, indiferentes, parciais, egoístas, são atitudes dependentes da condição básica da alteridade como corporeidade; atitudes assim caracterizadas que o são apenas porque são “atitudes para com uma alma”, respostas à superfície da corporeidade, visões da alteridade como um corpo compartilhado. O que significa dizer que os conceitos de compaixão, generosidade, amor, piedade, crueldade, indiferença, egoísmo, estão ancorados no mundo - no mundo da corporeidade - e são construídos na linguagem como conceitos dependentes de nossa condição compartilhada de criaturas. Sendo assim, nossa linguagem é corporificada porque 'corpo' é um conceito determinante para a formação de outros de nossos conceitos e para a formação de nossa linguagem tomada em sua amplitude.

Eu não estou afirmando que este é o único conceito fundacional para os nossos modos interrelacionais de operar com a linguagem (em vista da moralidade, sobretudo) - porque se estamos aqui lidando com um território conceitual alternativo que é uma rede ou uma teia, não devemos cair novamente na cilada das investigações essencialistas para a qual Wittgenstein já nos alertou o suficiente há bastante tempo - e eu gostaria de mencionar, sem desenvolver por enquanto, que outros destes conceitos estruturantes são 'vulnerabilidade', 'dignidade' e 'amor', os quais também estão relacionados de diversas maneiras, é claro, à criaturidade e, em se tratando de uma teia, é inescapável que seja assim. Aqui, a imagem de um caleidoscópio pode ser útil para visualizarmos a composição de diferentes figuras conceituais a partir de uma mesma perspectiva que, no entanto, sofre mudanças de aspecto conforme se deseje compreender com maior profundidade e lucidez um dos pontos interseccionais da teia. O ponto em questão, neste momento, é o 'corpo vivo'. E ele é necessariamente atravessado por outros conceitos porque é "do meio das coisas" e "do meio dos outros" que o enxergamos.

Evidentemente, é neste sentido que nossa linguagem é também corporificada por inflexões de poder. Trata-se de reconhecer na linguagem a vigência e a legitimidade

7 GAITA, O cão do filósofo, p.206. 
de um determinado tipo de vida que, privilegiadamente, parece poder tomar corpo. Em detrimento de outros corpos vivos. E ‘tomar corpo' aqui, significa, então, tomar poder e presciência, através de uma linguagem que se pretende como inquestionável, sobre tudo aquilo que, para esta perspectiva contextualizada e localizada sobre sua própria arrogância, não passa, no fim das contas e paradoxalmente, de "pura corporeidade". É assim que apenas um tipo de corpo assume a corporificação da linguagem ao pretender torná-la, per impossibile, conceitualmente incorpórea e imaterial - abstrata, idealizada, eminentemente "racional" - e ao outorgar a estes conceitos o critério do que conta como uma 'vida' passível de dignidade, honra e justiça - mas também, muitas vezes, basicamente, de humanidade. Eu estou falando de uma corporificação na linguagem de algo que é gramaticalmente anterior àquilo que Judith Butler qualifica como uma 'vida passível de luto', em seus últimos trabalhos, e que de certa forma estrutura também este enviesamento particular além de outros. Eu estou atribuindo à maneira como o poder legitima e mantém uma determinada conceituação a respeito do 'corpo', da 'vida' e da própria 'linguagem' sobretudo ao longo da história da filosofia - não apenas a nossa inaptidão para um mundo mais vivível mesmo quando o desejamos, mas também todas as exclusões de cunho moral e político que resultam em racismo, em misoginia e machismo, em transfobias, em ideologias colonialistas, imperialistas e monoculturais, e em desconsideração generalizada pela animalidade não humana e seu consequente carnivorismo. Eu estou falando sobre o modo como a linguagem molda e marca a realidade e todos os corpos, seja com o selo da legitimidade branca, masculina e heteronormativa em sua prerrogativa universal, seja com o selo da insuficiência humana para aquelas e aqueles, humanos ou não humanos, que vivem a vida, como se fosse erradamente, em seus corpos particulares, não universalizáveis, cujas experiências de vulnerabilidade depõem contra si mesmos em um mundo tornado unilateral até mesmo relativamente aos significados do sofrimento. Eu estou falando sobre o modo como a linguagem - e o campo das conceituações filosóficas em específico - estabelece os sentidos da autenticidade, aceitabilidade e adequação daquilo que conta ou não como uma 'vida' digna de consideração, como 'dignidade', como 'justiça', como 'moralidade', como 'ética', como 'conhecimento', como 'verdade' e, evidentemente, como 'filosofia' - a nulificação de certos textos, "literários”, metodologicamente interseccionais, e às vezes até interdisciplinares, como não sendo 'filosofia' constituindo uma atitude típica da linguagem corporificada atravessada pelo poder. Os critérios de uma corporeidade que é mascarada de intangibilidade estabelecem, assim, os cânones filosóficos e conceituais sob os quais todo o resto é considerado como parcialidade tendenciosa sem a assunção, evidentemente, de sua própria tendência.

É também neste sentido que se inscrevem as denúncias e críticas das epistemologias feministas e vertentes contemporâneas da filosofia política feminista, ambas sob o signo de uma revisão da história da filosofia - e, muitas vezes, portanto, de uma revisão dos seus conceitos. Não pretendo aqui de forma alguma sumarizar o extenso trabalho já realizado nesta seara em detrimento de uma reflexão intensamente comprometida com sua complexidade - para o que remeto a leituras presentes nas referências. Eu gostaria apenas de salientar o modo como o presente ensaio pressupõe a intersecção de questões morais, políticas e epistemológicas nisto que pretendo seja uma investigação metaética em rede e os possíveis rumos de seu aprofundamento.

Gaita fala de "devolver o corpo ao campo do significado" e resgatá-lo, no que diz respeito à sexualidade, por exemplo, "da natureza impenetrável da terminologia quase médica" . Ora, este resgate é também um resgate relativo à terminologia universalista e legalista cujo achatamento na linguagem reflete a ojeriza das diferenças e da pluralidade,

GAITA, O cão do filósofo, p.219. 
e da complexidade - da linguagem, dos corpos e das vidas, e sua irresolução escancarada na necessidade de se tomar perspectivas flexíveis, não unívocas, permeáveis a ressalvas, condições e contextos. Esta permeabilidade vai de encontro às dicotomias hierárquicas de longa data que são o alvo das denúncias feministas no discurso epistemológico e político cuja implosão resulta, entre outras asserções, no reconhecimento da linguagem e do conhecimento como corporificados, da construção do saber como localizado e generificado, e do corpo como sempre, inescapavelmente, político. O slogan de que “o pessoal é político" é central para se compreender as demandas da filosofia política feminista relativamente a uma outra das muitas dicotomias que acompanham os critérios conceituais - metodológicos e normativos - das teorias políticas canônicas ao tornar visível que as oposições público versus privado versus doméstico são construídas sobre e resultam em concepções excludentes e violentas do fazer político. Afinal, os polos reguladores dos pares de opostos que legitimam o espaço do discurso e das demandas políticas como espaço público são os polos que legitimam o discurso, o político, o público - assim como a filosofia, a racionalidade e a universalidade - como masculino, "neutro" e "imparcial". Trata-se da outorga da político como limitado, pelo poder e pela linguagem, a questões publicizáveis, e daquilo que é público a questões legisláveis (quase) universalmente. Daí a facilidade com que se instauram e se mantêm os vários níveis de exclusão das mulheres, dos negros e lgbtqi das discussões públicas, porque o "espaço privado" é tomado como a-político e questões de sexo, identidade de gênero e raça são tidas como alheias à interferência "pública”. Daí a facilidade também com que o "espaço privado" se confunde e se esconde como "espaço doméstico", onde a violência, as tarefas domésticas, a socialização e educação das crianças, e as relações com os animais não humanos estão livres de controle e responsabilização. Livres do político. A ênfase na politização do privado, do doméstico e do pessoal pretende, assim, expor as maneiras como determinada outorga no âmbito da linguagem incide sobre outras tantas concessões excludentes - e Carole Pateman, em sua revisão do contrato social como um contrato sexual, nos conta o desenrolar desta história desde o paternalismo até o patriarcado moderno de modo a não escusar ninguém em seu caminho, assim como Charles Mills o faz relativamente ao contrato racial.

Mas é a ênfase na politização do 'corpo' que eu gostaria de sugerir como sendo gramaticalmente nevrálgica para a permeabilidade e a flexibilidade de nossas reflexões sobre a moralidade - o que supõe, evidentemente, a permeabilidade da própria linguagem e de nossas perspectivas epistemológicas à política. O 'corpo' é político porque é à sua superfície que reagimos como "a uma alma”, e são nossas reações, estruturadas pelos modos contextualizados, particularizados e conversacionais de falar sobre a alteridade, e pelos valores absolutos (porque fundacionais) que orientam nossas relações, que incidem sobre nossas concepções e ações no mundo da criaturidade. Nossas atitudes, aqui, são atitudes políticas. Nossas visões sobre a alteridade são visões políticas. Elas marcam os corpos como passíveis de mais ou menos dignidade, de mais ou menos compaixão, de mais ou menos honradez, de mais ou menos preciosidade. Elas marcam os corpos como mais ou menos pertencentes à "comunidade moral". Como mais ou menos passíveis de responsividade.

Minha insistência aqui é pelo reconhecimento do corpo como político. Como o é por sua centralidade para nossas reflexões morais. Não se trata de novidade, mas de um resgate para o campo do significado e para nossas aspirações por lucidez e profundidade - se estivermos dispostos a encarar a complexidade da teia. Reconhecê-lo assim, insisto, é talvez o que nos permite reconhecer os significados envolvidos no próprio conceito de 'responsabilidade', o fato de sermos responsáveis pela alteridade porque somos a ela responsivos, o fato de que nossas respostas são atravessadas por conceitos por ela construídos e de que, portanto, nossa linguagem epistêmica, moral e política, é 
corporificada. De que, então, o corpo é fundacional para qualquer conversa acerca de uma reforma conceitual possível em vista de um mundo mais vivível. Que nos torne conceitualmente aptos para compreender o que significa viver como um corpo, o que significa ser vulnerável e, por isso, precioso, o que significa compartilhar da criaturidade até o ponto em que talvez possamos nos tornar conceitualmente aptos a compreender o que significa "viver como um cachorro".

Para finalizar, eu gostaria de sugerir que esta reforma conceitual aqui almejada, que é política e metodologicamente interseccional, engendra necessariamente um quadro alternativo no que diz respeito às nossas construções textuais. Penso aqui não apenas no modo como o reconhecimento de nossa linguagem corporificada requer uma linguagem - moral e política - responsiva, ao invés de normativa e/ou universalista, mas também no modo como o texto filosófico pode ele mesmo comportar estas características de abertura, flexibilidade e permeabilidade. Já me manifestei em outros momentos contra a "clausura da norma” e contra a clausura do artigos filosóficos devotados ao linguajar acadêmico muitas vezes meramente exegéticos e insulados a uma argumentação entre pares - em prol de uma filosofia literariamente engajada9. Sem voltar aos traços aí aventados como possíveis para uma metodologia filosófica aberta à complexidade da vida, registro apenas que a escritura de Raimond Gaita conta como exemplo por excelência do reconhecimento da inseparabilidade entre forma e conteúdo. O cão do filósofo empreende em ato a reivindicação do próprio autor por uma reflexão vivida "com essa parte da linguagem" que "se torna viva para nós, em seu uso criativo, na narrativa e na poesia, no teatro ou no cinema (...) quando somos tocados em nossa emoção" ${ }^{10}$. É isso o que ele mesmo realiza. E é isso o que contemporaneamente proponho que façamos se queremos lutar contra o nefasto e social e politicamente desengajado hermetismo da academia filosófica.

Esta proposta se integra ao requerimento de uma linguagem - moral e política responsiva contra o tipo de linguagem legalista que tem sido privilegiado por nossas construções teóricas em ética. O apelo ao significado de nossas expressões, de nossos modos de falar sobre a alteridade e de nossos modos de agir no mundo é um apelo ao nosso entendimento tal como moldado por nossa atitude para com o mundo e para com a vida - e que, por sua vez, é estrutural e conceitualmente moldada por nossa condição compartilhada de criaturidade. Essa atitude pode ou não participar daquilo que Gaita chama de "compreensão do mundo como uma dádiva” - e que já estava presente nas reflexões de Wittgenstein desde o Diário Filosófico em diante. Mas ela certamente participa de nossa capacidade de resposta - de nossa abertura e prontidão para responder ao mundo e à vida e, portanto, à alteridade. É claro que podemos responder ao mundo de muitos modos e muitas vezes sem a disciplina da lucidez e da sobriedade ou sob os efeitos enviesados do preconceito, do egoísmo e do poder inebriante. No entanto, deveres, obrigações e princípios, se alteram alguma coisa em nossas respostas, o fazem tão somente formalmente e são ineficazes como remédio à nossa cegueira semântica e incapazes, por si sós, de "fazer ver" a alteridade. "Ver" é, por assim dizer, uma questão de espírito. E não de lei. Trata-se, portanto, de tornar a alteridade visível à nossa capacidade de resposta, e essa é uma tarefa para o que estou chamando aqui de linguagem responsiva cujos conceitos são os valores absolutos fundacionais à nossa compreensão e ancoragem contextualizada como corpos vivos, de novo: amor, justiça, generosidade, dignidade, piedade, compaixão, beleza. Não tenho aqui a intenção, e sequer ainda o fôlego, para marcar os pontos de intersecção destes conceitos e desta linguagem na teia estruturante de significados de minhas incursões metaéticas, mas creio que por ora seja suficiente dizer que o apelo à nossa capacidade de responder com amor, com justiça, com generosidade, com piedade é um apelo ao espírito com que nos colocamos no mundo de modo a desejarmos torná-lo mais

\footnotetext{
${ }_{9}$ Cf. Sattler 2016, 2016a, 2017.

${ }^{10}$ GAITA, O cão do filósofo, p.113.
} 
vivível - de modo a nos tornarmos conceitualmente mais aptos para a única vida que há, vivida em nossos corpos humildemente reconhecidos como corpos. Esta linguagem talvez nos permita responder mais lucidamente e sem arrogância à nossa própria animalidade e aos nossos companheiros de criaturidade.

Em última instância, se nossa capacidade de resposta depende de nossa capacidade de visão e se se trata de uma questão de espírito, então talvez nossa tarefa em direção à uma linguagem responsiva e à permeabilidade de nossas reflexões morais seja aquela há muito empreendida pela literatura: fazer ver as coisas como elas são com o coração de um corpo vivo.

\section{Referências}

ALCOFF, Linda e Potter, Elisabeth. Feminist Epistemologies. New York and London: Routledge, 1993.

BUTLER, Judith. Quadros de Guerra: Quando a vida é passível de luto? Tradução: Sergio Lamarão e Arnaldo Marques da Cunha. São Paulo: Civilização Brasileira, 2015.

BUTLER, Judith. Precarious Life. The Powers of Mourning and Violence. London \& New York: Verso, 2004.

COETZEE, J.M. Desonra. Tradução: José Rubens Siqueira. São Paulo: Cia das Letras, 2000.

COETZEE, J.M. A vida dos animais. Tradução: José Rubens Siqueira. Introdução e organização: Amy Gutmann. São Paulo, 2002.

GAITA, Raimond. O cão do filósofo. Tradução: Maria Lúcia Daflon. Rio de Janeiro: DIFEL, 2011.

HARAWAY, Donna. 'Saberes localizados: a questão da ciência para o feminismo e o privilégio da perspectiva parcial'. Cadernos Pagu (5), Núcleo de Estudos de Gênero - Pagu/ Unicamp, 1995, pp.7-42.

HARDING, Sandra. “Is there a feminist method?” In: Feminism and methodology: Social science issues. Bloomington: Indiana University Press, 1987.

HARDING, Sandra. The science question in feminism. Ithaca: Cornell University Press, 1986.

LEVI, Primo. É isto um homem? Tradução: Luigi Del Re. Rio de Janeiro: Rocco, 1988.

LONGINO, Helen. The fate of knowledge. Princeton: Princeton University Press, 2001.

MILLS, Charles W. The Racial Contract. Ithaca: Cornell University Press, 1997.

PATEMAN, Carole. O contrato sexual. Tradução: Marta Avancini. Rio de Janeiro: Paz e Terra, 1993.

RAGO, Margareth. “Epistemologia Feminista, Gênero e História”. In: Masculino, feminino, plural. Pedro, J.M. e Grossi, M. (orgs.). Florianópolis: Ed. Mulheres, 1998.

SATTLER, Janyne. “'Aprender a cair”: Nussbaum, Coetzee, Gaita'. Veritas. Porto Alegre, v.61, n.2, maio-ago. 2016, p.407-424.

SATTLER, Janyne. 'Contra o “ar rarefeito da teoria moral”. Revista Ethic@. Florianópolis, Santa Catarina, Brasil, v.15, n.2, p.246-259. Nov. 2016a.

SATTLER, Janyne. 'Playing ethics and teaching morality: how Wittgenstein could help us to apply games to the moral living'. Trans/form/ação. Trans/Form/Ação, Marília, v. 40, n. 4, p. 89-110 Out./Dez., 2017.

WITTGENSTEIN, Ludwig. Carnets 1914-1916. Gallimard: 2005.

WITTGENSTEIN, Ludwig. Investigações Filosóficas. Tradução: Carlos Bruni. São Paulo: Nova Cultural, 1999. 